\title{
Extended septal myectomy for hypertrophic obstructive cardiomyopathy with anomalous mitral papillary muscles or chordae
}

\author{
Kenji Minakata, MD \\ Joseph A. Dearani, $\mathrm{MD}^{\mathrm{a}}$ \\ Rick A. Nishimura, $M D^{\mathrm{b}}$ \\ Barry J. Maron, MD ${ }^{\mathrm{c}}$ \\ Gordon K. Danielson, MDa
} From the Divisions of Cardiovascular Sur-
gery $^{\mathrm{a}}$ and Cardiovascular Diseases, ${ }^{\text {b Mayo }}$
Clinic, Rochester, Minn, and The Hypertro-
phic Cardiomyopathy Center, ${ }^{\mathrm{c}}$ Minneapolis
Heart Institute Foundation, Minneapolis,
Minn.

Read at the Eighty-third Annual Meeting of The American Association for Thoracic Surgery, Boston, Mass, May 4-7, 2003.

Received for publication May 20, 2003; revisions requested Sept 23, 2003; accepted for publication Sept 29, 2003.

Address for reprints: Joseph A. Dearani, MD, 200 First Street SW, Rochester, MN 55905 (E-mail: dearani.joseph@mayo. edu).

J Thorac Cardiovasc Surg 2004;127:481-9 $0022-5223 / \$ 30.00$

Copyright (C) 2004 by The American Association for Thoracic Surgery

doi:10.1016/j.jtcvs.2003.09.040
Objectives: Transaortic left ventricular septal myectomy yields excellent results for most severely symptomatic patients with hypertrophic obstructive cardiomyopathy. However, associated anomalies of the mitral subvalvular apparatus may prevent complete relief of obstruction, and mitral valve replacement has been advocated. We reviewed our results of procedures designed to relieve obstruction with preservation of the mitral valve.

Methods: Among 291 patients undergoing septal myectomy from 1975 to 2002, 56 (ages 2-77 years) had anomalous mitral subvalvular apparatus including anomalous chordae $(\mathrm{n}=28)$ and papillary muscles with direct insertion into mitral leaflets $(\mathrm{n}$ $=13)$ or fusion to septum $(n=31)$ or free wall $(n=12) ; 82 \%$ of patients were in New York Heart Association class III or IV. Operation included resection of anomalous chordae (28 patients), relief of papillary muscle fusion (36 patients), and extended septal myectomy, wider at the apex than the base.

Results: There were no early deaths and no patients required mitral valve replacement. Mean peak pressure gradients decreased from $70 \pm 28$ to $4.9 \pm 8.4 \mathrm{~mm} \mathrm{Hg}$ and mean mitral regurgitation grade decreased from 2.3 to $1.0(P<.001)$. Mean follow-up was $2.8 \pm 2.6$ years. Freedom from reoperation at 4 years was $95 \%$. There were 3 late noncardiac deaths; $98 \%$ of patients were in New York Heart Association class I or II.

Conclusions: Hypertrophic obstructive cardiomyopathy associated with anomalous mitral papillary muscles or chordae can be successfully treated without mitral valve replacement by surgical relief of the anomalies and an extended septal myectomy; early mortality is low, obstruction and mitral regurgitation are significantly reduced, and late results are excellent.

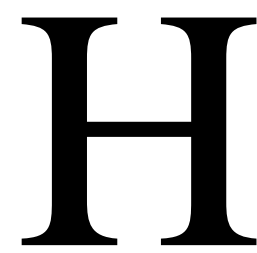
ypertrophic cardiomyopathy is a primary genetic myocardial disease. ${ }^{1}$ Its heterogeneity is well documented in terms of clinical manifestations, hemodynamic characteristics, anatomic morphology, and natural history. ${ }^{1,2}$ Many patients have variable degrees of dynamic left ventricular outflow tract obstruction (LVOTO) due to systolic anterior motion (SAM) of the anterior mitral leaflet. SAM is also responsible for concomitant mitral regurgitation, which is typically directed posterolaterally into the left atrium. ${ }^{3}$

Most patients' symptoms are controlled medically, but 5\% of all patients in primary care settings and up to $30 \%$ in populations referred to large medical centers have a marked outflow gradient at rest or with provocation associated with severely limiting symptoms unresponsive to maximal medical therapy. ${ }^{4}$ For 
TABLE 1. Patient demographics

\begin{tabular}{lc}
\hline Variables & Number (\%) \\
\hline Family history of HCM & $19(34)$ \\
Preoperative symptoms* & \\
$\quad$ Dyspnea & $53(95)$ \\
Angina & $25(45)$ \\
Syncope/presyncope & $21(38)$ \\
History of atrial fibrillation & $11(20)$ \\
History of ventricular tachycardia & $3(5)$ \\
Preoperative medicationst & \\
Beta-blocker & $37(66)$ \\
Calcium antagonist & $28(50)$ \\
Other antiarrhythmic agents & $9(16)$ \\
Prior dual chamber pacemaker & $11(20)$ \\
Prior ICD implant & $3(5)$
\end{tabular}

HCM, Hypertropic cardiomyopathy; $I C D$, implantable cardioverter defibrillator.

*Some patients had more than 1 symptom.

tSome patients took more than 1 cardiac medication.

these patients, left ventricular septal myectomy, also known as the Morrow procedure, has been the standard therapeutic option for children and adults. ${ }^{5-11}$

Classical septal myectomy effectively abolishes LVOTO, SAM, and associated mitral regurgitation and yields excellent late results. However, some symptomatic patients with hypertrophic obstructive cardiomyopathy (HOCM) have associated anomalies of the mitral subvalvular apparatus that if unrecognized and untreated can lead to intraoperative death or incomplete or only temporary relief of obstruction. ${ }^{12,13}$ Perhaps the most important of these anomalies is anomalous papillary muscle insertion directly into the anterior mitral leaflet, an entity that has been well documented by Klues and associates. ${ }^{12,13}$ Mitral valve replacement has been advocated by some as the best surgical solution for this serious anomaly. Other anomalies of mitral subvalvular apparatus include extensive fusion of papillary muscles with the ventricular septum or left ventricular free wall, abnormal chordae tendineae (false cords) that attach to the ventricular septum or free wall, and accessory papillary muscles, all of which may tether the mitral leaflets toward the septum and produce LVOTO. Additional mechanisms of dynamic LVOTO, which are not necessarily related to papillary muscle anomalies, include midventricular obstruction secondary to severely hypertrophied papillary muscles or other muscle bundles ${ }^{14}$ and anterior displacement of the anterolateral papillary muscle. ${ }^{15}$

Increasing awareness of the importance of anomalies of the mitral subvalvular apparatus and improved ability to visualize subvalvular structures by means of optical magnification and fiber-optic lighting have led to their increased identification and successful surgical treatment. ${ }^{11-14,16}$ This article reviews the early and late results of patients who have undergone operation for HOCM associated with anomalies of the mitral subvalvular apparatus.

\section{Patient and Methods}

Between April 1975 and August 2002, 291 patients underwent operation for HOCM at the Mayo Clinic. In the early part of the series, the diagnosis of HOCM was based on clinical evaluation and cardiac catheterization. More recently, cardiac catheterization has been supplanted by echocardiography and is performed only when supplemental information is required. Examples include evaluation of dynamic obstruction under monitored conditions in symptomatic patients for whom satisfactory echocardiographic pressure gradients cannot be obtained during exercise, or evaluation of coronary arteries in patients at risk for coronary artery disease. Indications for operation included patients with severe symptoms unresponsive to or intolerant of optimal medical therapy with left ventricular outflow tract (LVOT) pressure gradients greater than or equal to $50 \mathrm{~mm} \mathrm{Hg}$ (measured with Doppler echocardiography either under resting conditions and/or with provocation, preferably utilizing physiologic exercise). Anomalies of the mitral subvalvular mechanism were often suspected or confirmed preoperatively by echocardiography, but the exact anatomical details were defined intraoperatively. ${ }^{14}$ Patients with combined severe right ventricular outflow tract obstruction as well as LVOTO who underwent biventricular septal resections were excluded from this review $(\mathrm{n}=9)$.

Regarding the overall series of 291 patients, early mortality was $0 \%$ for the 200 patients undergoing isolated septal myectomy and $1 \%(\mathrm{n}=3)$ for the entire series, which included concomitant cardiac procedures such as valve replacement and myocardial revascularization.

Fifty-six of the 291 patients (19\%) were found to have anomalous mitral subvalvular apparatus, and they form the cohort for this review. There were 23 men and 33 women with ages ranging from 2 to 77 years (mean $42 \pm 20$, median 43). Patient demographics are summarized in Table 1. Eleven patients who had undergone prior dual chamber pacemaker implantation had received only temporary $(n=6)$ or insignificant $(n=5)$ relief of symptoms and gradients. The mean interval between permanent pacemaker implantation and septal myectomy was $4.1 \pm 2.5$ years. Three patients considered to be at high risk for sudden death had undergone implantable cardioverter defibrillator (ICD) implantation elsewhere prior to septal myectomy. The indications for prior implantation of ICD included history of cardiac arrest, ventricular tachycardia, and strong family history of sudden deaths in 1 patient each.

One patient (patient A) had previously undergone a classical myectomy at age 5 years with significant reduction of LVOT gradient and degree of mitral regurgitation, at which time anomalies of his subvalvular mechanism were not recognized. However, he entered the cohort of this review when reoperation was necessary 10 years later because of recurrent LVOTO and severe mitral regurgitation.

Preoperatively, $82 \%(n=46)$ of the patients were New York Heart Association (NYHA) class III or IV (Figure 1). Only 1 patient was asymptomatic, a 14-year-old boy who was observed to have rapid progression of LVOTO and mitral regurgitation; his peak systolic gradient was $93 \mathrm{~mm} \mathrm{Hg}$. Preoperative hemodynamic and echocardiographic data are shown in Table 2. 


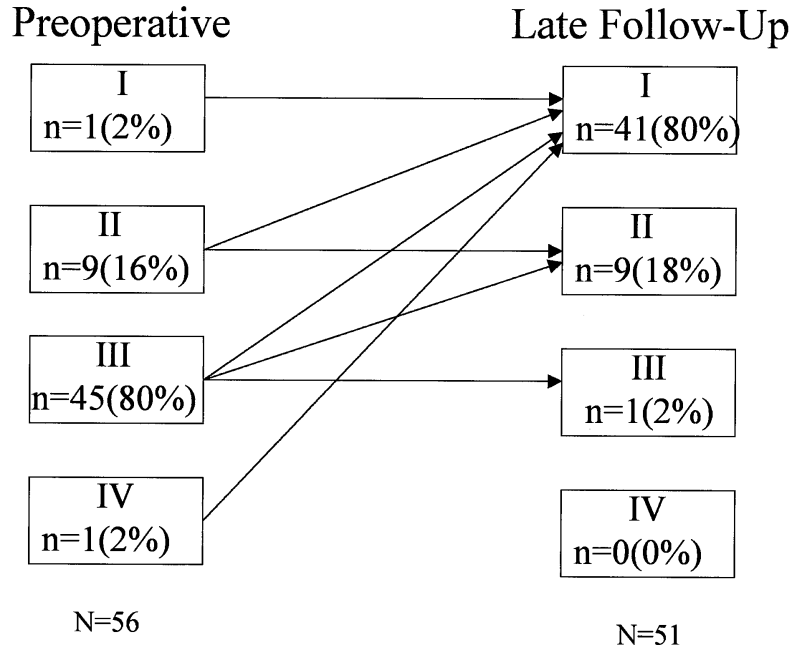

Figure 1. New York Heart Association functional classes preoperatively and at late follow-up.

\section{Echocardiographic Findings}

It is possible to identify mitral apparatus anomalies such as direct papillary muscle insertion into mitral valve with either transthoracic echocardiography at clinical evaluation or transesophageal echocardiography in the operating room. Images obtained in the parasternal long-axis or apical cross-sectional planes may suggest that a papillary muscle and the mitral valve are contiguous by virtue of a rigid (ie, nonflexible) motion pattern during the cardiac cycle, no evidence of chordae interpositioned between papillary muscle and mitral valve, and midventricular muscular apposition between papillary muscle and ventricular septum during systole. Usually, SAM is absent or mild without mitral-septal contact, and the level of obstruction can be demonstrated with pulsed Doppler to be midventricular. On occasion, SAM can be evident (even with mitral-septal contact), presumably emanating from a free edge of anterior mitral leaflet removed from the site of anomalous papillary muscle insertion. It should be emphasized that clinical identification of mitral apparatus anomalies, particularly direct papillary muscle insertion into mitral valve, may be exceedingly difficult even for expert echocardiographers (including those knowledgeable regarding hypertrophic cardiomyopathy), as it may require nonstandard (off-center) cross-sectional imaging planes not oriented through the midcavity of the left ventricle because anomalous papillary muscles do not necessarily attach to the mitral valve in the central portion of the leaflet. Anomalous chordae tendineae within the LVOT, oriented in a variety of directions and usually attaching to papillary muscles and ventricular septum, also may sometimes be identifiable with echocardiography.

In this series, the diagnosis of anomalous papillary muscles was first made by preoperative transthoracic echocardiography $(\mathrm{n}=$ 11), intraoperative transesophageal echocardiography (TEE) $(\mathrm{n}=$ $4)$, or direct inspection at the time of operation $(n=30)$.

\section{Current Surgical Techniques}

Intraoperative TEE is performed after induction of general anesthesia, with particular attention to the cardiac anatomy, mitral
TABLE 2. Hemodynamic and echocardiographic data

Premyectomy Postmyectomy $P$ value

LVOT peak pressure gradient

(mm Hg)

TTE

Median

Intraoperative direct

measurement $(\mathrm{mm} \mathrm{Hg})$

Median

Mean MR grade (TEE)

None (0/4)

Trivial/mild (1/4)

Moderate (2/4)

Moderately severe (3/4)

Severe (4/4)

Mean AR grade (TEE)

None (0/4)

Trivial/mild $(1 / 4)$

Moderate (2/4)

Moderately severe (3/4)

Severe $(4 / 4)$

Mean LVEF (\%) (TTE)

(1)

$\begin{array}{ccc}97 \pm 34 & 11 \pm 11 & <.001 \\ 92 & 12 & \\ 70 \pm 28 & 4.9 \pm 8.4 & <.001 \\ & & \\ 66 & 1 & \\ 2.3 \pm 1.2 & 1.0 \pm 0.5 & <.001 \\ 3(5 \%) & 8(14 \%) & \\ 16(29 \%) & 43(77 \%) & \\ 18(32 \%) & 5(9 \%) & \\ 5(9 \%) & 0(0 \%) & \\ 14(25 \%) & 0(0 \%) & \\ 0.33 \pm 0.52 & 0.42 \pm 0.50 & \text { NS } \\ 41(73 \%) & 37(66 \%) & \\ 14(25 \%) & 19(33 \%) & \\ 1(2 \%) & 0(0 \%) & \\ 0(0 \%) & 0(0 \%) & \\ 0(0 \%) & 0(0 \%) & \\ 74 \pm 5.7 & 72 \pm 6.7 & \text { NS }\end{array}$

$A R$, Aortic regurgitation; $L V E F$, left ventricular ejection fraction; $L V O T$, left ventricular outflow tract; $M R$, mitral regurgitation; $T E E$, intraoperative transesophageal echocardiography; TTE, transthoracic echocardiography preoperatively and at hospital discharge.

valve function, and thickness of the ventricular septum. Exposure is gained through a median sternotomy and pressures are measured in all 4 cardiac chambers and aorta. If the right ventricular pressure is elevated, pulmonary arterial pressure is also measured to evaluate possible right ventricular outflow tract obstruction or pulmonary hypertension. Standard cardiopulmonary bypass with moderate hypothermia $\left(28^{\circ} \mathrm{C}-32^{\circ} \mathrm{C}\right)$ is used and the left heart is vented. Myocardial protection, especially important because of the severe ventricular hypertrophy, is begun with a generous infusion of cold blood cardioplegic solution into the aortic root followed by additional doses given selectively into the left and right coronary ostia every 20 minutes. Topical cooling with ice-slush saline solution is also applied, and an insulating pad is placed behind the left ventricle during the more complex procedures. A transverse aortotomy is made, carried rightward toward the noncoronary sinus, and retracted with pledgeted sutures. The aortic wall at the distal valve commissures is suspended with pledgeted sutures attached to the drapes or wound edges to maximize exposure of the hypertrophied septum and anterior mitral leaflet.

The classical portion of the resection is begun by making 2 parallel longitudinal incisions in the septum, the first beneath the nadir of the right coronary cusp and the second beneath the commissure between the right and the left coronary cusps. These incisions are connected superiorly with a third incision 1.0 to 1.5 $\mathrm{cm}$ below the aortic valve, and a deep wedge of septal tissue is resected (Figure 2, A). Care is taken to carry the incision apically beyond the point of mitral-septal contact (marked by the fibrous friction lesion; Figure 2, A). This classical resection is then extended in several ways, beginning with continued resection leftward toward the mitral valve annulus and apically to the bases of 

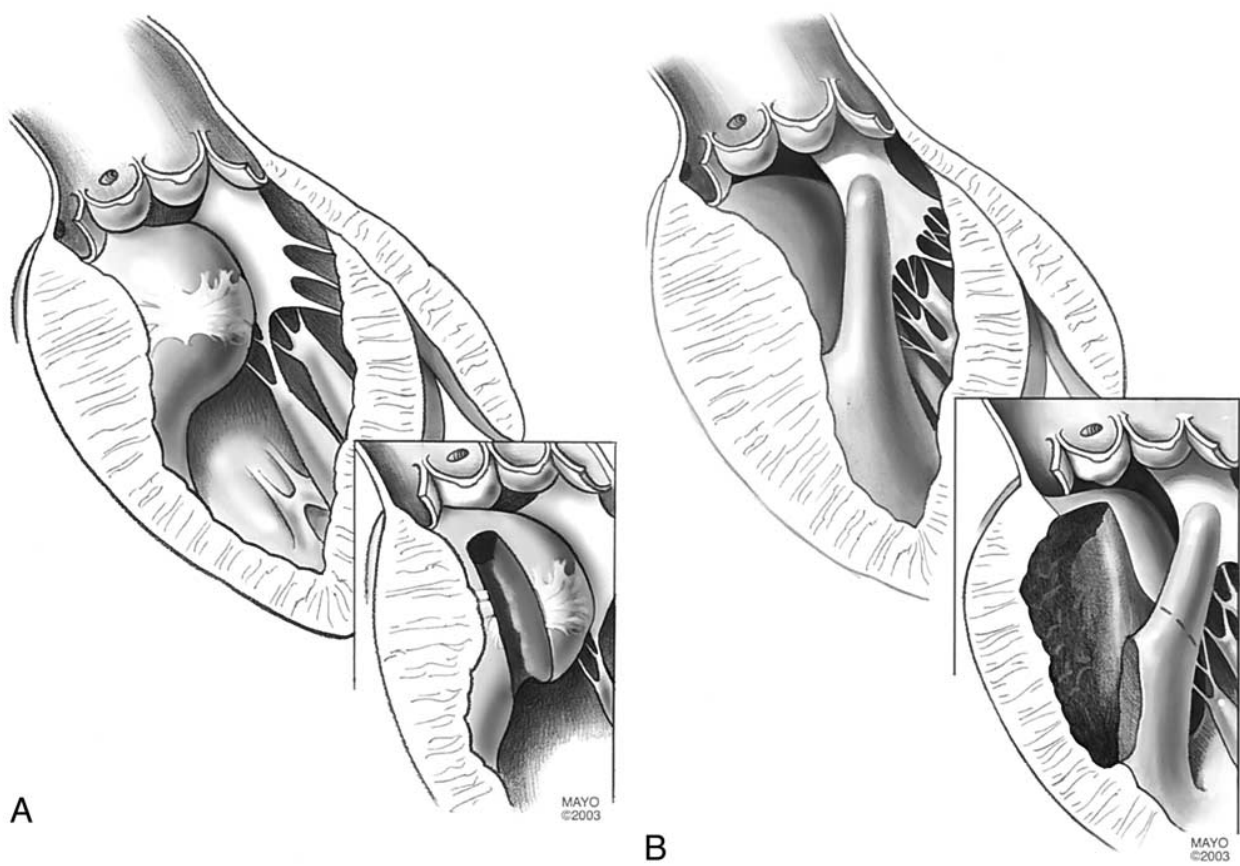

Figure 2. A (left), Classic left ventricular septal myectomy for hypertrophic obstructive cardiomyopathy. B (right), Extended left ventricular septal myectomy for anomalous papillary muscle with direct insertion into anterior mitral leaflet and also fusion to the septum.

the papillary muscles. The apical third of the right side of the septum is then resected to obtain a much wider trough at the apex than the base (a laboratory flasklike configuration as shown in Figure 2, B). For midventricular obstruction due to hypertrophied papillary muscles or muscle bundles, additional resection is made around the bases of the papillary muscles. All areas of papillary muscle fusion to the septum or ventricular free wall are divided, ${ }^{11,14-16}$ and anomalous chordal structures and fibrous attachments of the mitral leaflets to the ventricular septum or free wall are divided or excised. All abnormal chordae attached to the free edge of the mitral leaflet are preserved to prevent flail leaflet. The adequacy and distal extent of the resection are evaluated by direct inspection and digital palpitation. After the patient is weaned from cardiopulmonary bypass, pressures are remeasured in the left ventricle and aorta and TEE evaluation is repeated.

Demographic and other patient-related data were obtained from medical records. Follow-up information was obtained from subsequent clinic visits, written correspondence from local physicians, and telephone interviews with patients or families.

The probability of survival and survivorship free of reoperation were estimated by the Kaplan-Meier method. Patient survival curves were compared with the expected curves of persons of the same age and sex as derived from vital statistics for the west north central region of the United States. The rank sum test was used to compare continuous variables. Data were expressed as mean \pm standard deviation. Early operative mortality was defined as death occurring within 30 days of operation or at any time during the index hospitalization. This study was approved by the Mayo Foundation Institutional Review Board, and patients or families gave informed consent.

\section{Anomalies of Mitral Subvalvular Apparatus}

The intraoperative findings of anomalies of mitral subvalvular apparatus are listed in Table 3 . In addition to the anomalies shown, the papillary muscles were often severely hypertrophied, creating additional obstruction at midventricular level. Anterior displacement of the anterolateral papillary muscle was common.

Anomalous papillary muscles constituted the subset most likely to create important LVOTO, especially those that inserted directly into the mitral leaflets (Figure 2,B). The degree of fusion of papillary muscles to the ventricular septum (Figure 2, $B$ ) or free wall varied from fusion of the base only to fusion of the entire length of the papillary muscle. A few patients had accessory papillary muscles (Figure 3,A) or fibrous fusion of a portion of the anterior mitral leaflet directly to the septum. These anomalies appeared to play a role in augmenting LVOTO by restricting mobility of the leaflets and/or tethering them toward the septum, thus narrowing the LVOT.

False cords arising from 1 or both papillary muscles and inserting into the ventricular septum or free wall were common (Figure 3, $A$ and $B$ ). When they were inspected in the relaxed heart, in most cases it was not possible to determine whether or not they contributed to the LVOTO. However, when they were encountered, they were resected or divided to improve mobility of the papillary muscles.

\section{Results}

The mean cardiopulmonary bypass time was $85 \pm 32$ minutes and the mean aortic crossclamp time was $58 \pm 15$ minutes. Concomitant procedures performed in 9 patients 
(all for preexisting conditions) included mitral valve repair $(\mathrm{n}=2)$, resection of additional discrete membranous subaortic stenosis $(n=2)$, aortic valve repair $(n=2)$, aortic valve replacement $(\mathrm{n}=1)$, radical pericardiectomy $(\mathrm{n}=1)$, and repair of Ebstein anomaly $(\mathrm{n}=1)$. Mitral valve replacement was not necessary in any patient.

Means of intraoperative direct measurements of peak systolic LVOT gradients pre- and postmyectomy are shown in Table 2; the decrease in mean gradient was highly significant. Intraoperative assessment of mitral regurgitation by TEE pre- and postmyectomy showed a concomitant highly significant reduction of mean echocardiographic grade (Table 2). There was no significant change in aortic regurgitation grade or left ventricular ejection fraction.

There were no early deaths. Early morbidity included atrial fibrillation necessitating antiarrhythmic drugs with or without cardioversion $(\mathrm{n}=11)$, need for permanent pacemaker $(\mathrm{n}=3)$ ( 2 of the 3 had isolated septal myectomy; 1 of the 2 had return of sinus rhythm on follow-up), and temporary neurological events $(\mathrm{n}=2)$. Seven patients who were considered to be at high risk for sudden death because of a strong family history of sudden death or nonsustained ventricular tachycardia on 24-hour electrocardiographic monitoring underwent elective placement of an ICD. Comparisons of mean transthoracic echocardiographic estimates of peak systolic LVOT gradients preoperatively and prior to hospital discharge showed a highly significant reduction at discharge (Table 2).

Follow-up obtained in 54 of 56 patients (96\%) ranged from 1 month to 13 years (mean $2.8 \pm 2.6$ years). There were 3 late deaths, all noncardiac, from chronic renal failure $(\mathrm{n}=2$, ages 42 and 82 years $)$ and stroke $(\mathrm{n}=1$, age 76 years). Probability of survival was $98 \%$ and $91 \%$ at 1 and 4 years, respectively (Figure 4 ). The difference between observed survival and expected survival was not statistically significant $(P=.08)$. Of the 51 late survivors followed, 98\% were in NYHA class I or II (Figure 1).

One 2-year-old patient (patient B), whose anomalies of mitral subvalvular apparatus were recognized at operation, subsequently required a second cardiac operation. At the first operation, multiple attachments of the posteromedial papillary muscle to the ventricular septum were noted, and midventricular obstruction was present. She also had severe mitral valve regurgitation from posterior leaflet prolapse. A planned extended myectomy was limited somewhat by the small size of aorta and restricted access to the subvalvular area. She improved postoperatively but subsequently redeveloped severe mitral regurgitation and a midventricular gradient $(34 \mathrm{~mm} \mathrm{Hg}$ ). Reoperation at age 5 included mitral valve repair (annuloplasty and posterior leaflet plication) and an extended midventricular resection; the LVOT gradient was reduced to $5 \mathrm{~mm} \mathrm{Hg}$. She is currently doing well and in NYHA class I.
TABLE 3. Intraoperative findings of anomalies of mitral subvalvular apparatus*

Anomalous papillary muscles

Direct insertion into anterior mitral leaflet $\quad 13$

Fusion to ventricular septum 31

Fusion to left ventricular free wall $\quad 12$

Accessory papillary muscle 2

Anomalous chordae tendineae (false cords) 28

Fusion of mitral leaflet to septum

3

*Some patients had more than 1 anomaly.

Three patients underwent late ICD implantation because of sudden death of a family member $(\mathrm{n}=2)$ or syncope ( $\mathrm{n}$ $=1)$.

Survivorship free of cardiac reoperation at 1 and 4 years was $100 \%$ and $95 \%$, respectively.

\section{Discussion}

Hypertrophic cardiomyopathy is characterized by inappropriate hypertrophy of the myocardium and is associated with various clinical presentations ranging from complete absence of symptoms to sudden, unexpected death. There is a subgroup of patients who develop severe limiting symptoms of dyspnea, angina, or syncope, or a combination of these, due primarily to dynamic obstruction of the LVOT and associated mitral regurgitation. The established medical therapy for patients with HOCM has been a trial of large doses of beta-blockers, calcium channel antagonists, or disopyramide, either alone or in combination. Operation has been the gold standard therapy for those severely symptomatic patients with fixed or inducible gradients who are intolerant of these medications or unresponsive to them. ${ }^{2,4}$

Surgical approaches for HOCM were first initiated in the late 1960s. The first surgical procedures proposed for relief of LVOTO were simple incision in the basal septal bulge, sometimes deepened with the surgeon's finger (myotomy), or excision of obstructing muscle under direct vision (myectomy). ${ }^{5}$ Historically, surgical exposure of the septum has been obtained through the aorta, left ventricle, right ventricle, or left atrium; the transaortic approach is now preferred by most surgeons. To preserve conduction tissue in the septum, the surgeon can remove tissue only in a specific location in the septum. Decrease or abolition of the LVOT gradient is accomplished not only by physical enlargement of the outflow tract but also by interruption of the pathophysiological events (primarily SAM) that cause the outflow gradient. Complete relief of LVOTO by septal myectomy results in correction of mitral regurgitation caused by SAM. Any residual mitral regurgitation due to ruptured chordae, mitral valve prolapse, or annular dilatation can usually be corrected by mitral valve repair and annuloplasty. ${ }^{17}$ 

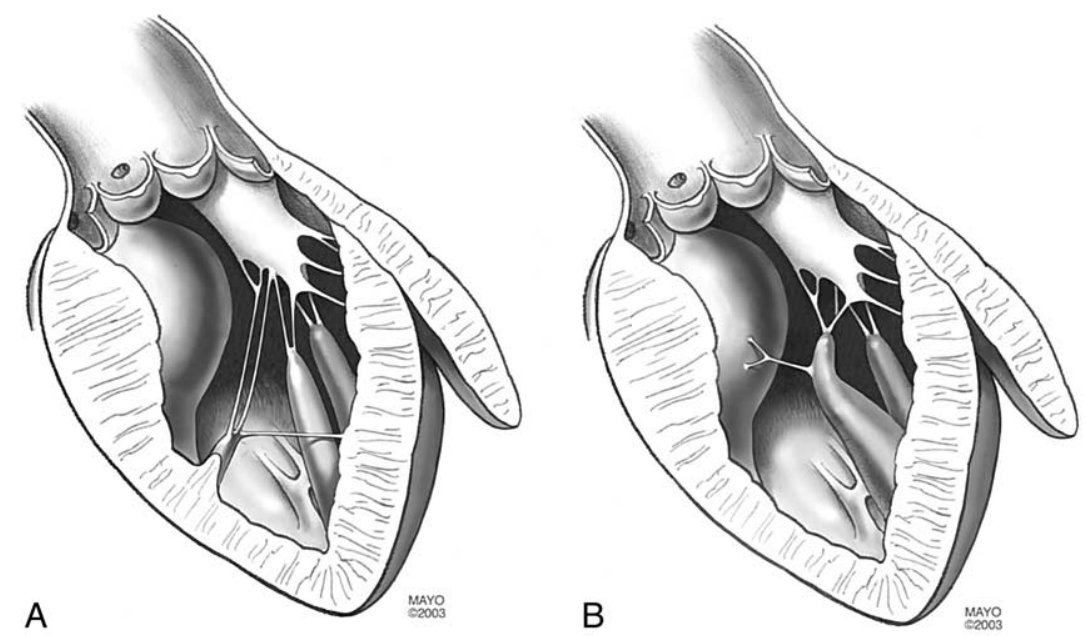

Figure 3. A (left), Accessory papillary muscle arising from the anterior free wall with chordal attachments to the mitral leaflet and free wall. B (right), Anomalous chordae tendineae arising from a papillary muscle and inserting into the septum.

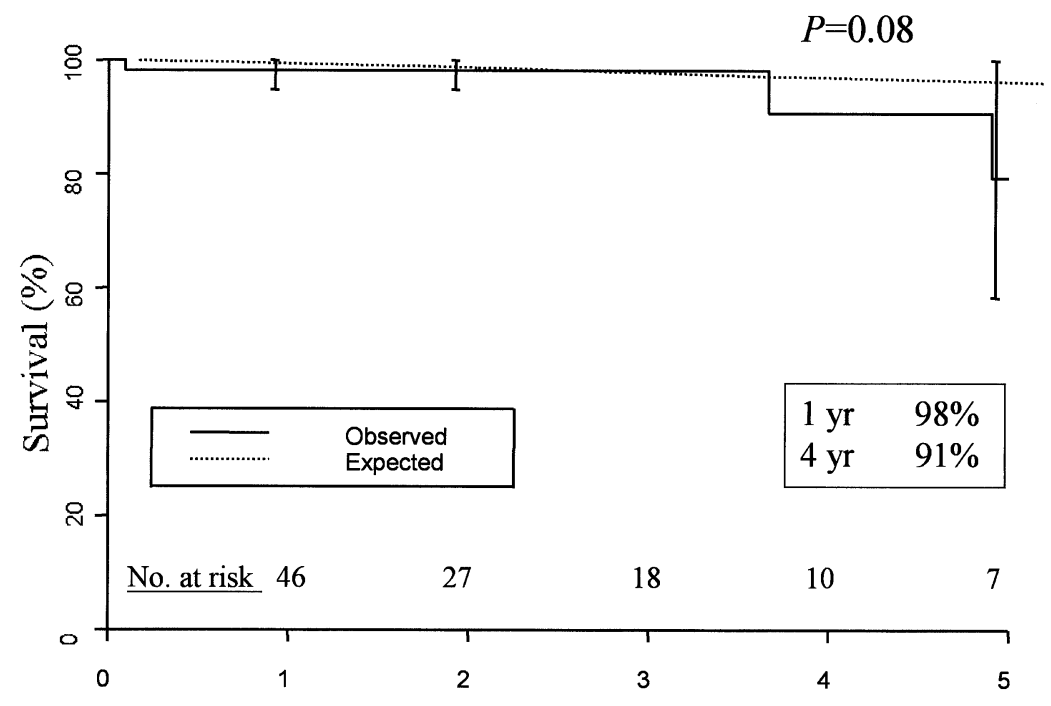

Years Since Surgery

Figure 4. Probability of patient survival compared with expected survival of persons of the same age and sex ( $P$ $=.08)$.

Replacement of the mitral valve with a low-profile mitral valve prosthesis-once proposed as an alternative to septal myectomy - also reduces the left ventricular outflow gradient and improves symptoms. ${ }^{18}$ The major disadvantage of this procedure is that 1 disease process is replaced with others such as problems of durability, infection, thromboembolism, and anticoagulation, which are associated with prosthetic valves. In general, mitral valve replacement is now reserved for significant mitral regurgitation in patients with primary mitral valve disease unsuitable for valve repair.

Papillary muscle anomalies are recognized with increasing frequency as causing or contributing to dynamic subaortic obstruction, usually but not always associated with SAM and mitral regurgitation, in some patients. ${ }^{4,11-14,16}$ In 1 report, an analysis of 78 mitral valves excised from patients undergoing operation for HOCM showed that 10 (13\%) had anomalous insertion of 1 or both left ventricular 
papillary muscles directly into the anterior mitral leaflet. ${ }^{13}$ If unrecognized and untreated, these anomalies can cause intraoperative death or incomplete or only temporary relief of obstruction.

These problems are exemplified by the 2 cases described in this report. Patient A's anomalies of mitral subvalvular apparatus were not recognized at the time of classical myectomy and were largely responsible for recurrence of severe LVOTO and mitral regurgitation, which necessitated reoperation 10 years later. Anomalies of subvalvular apparatus in patient B (age 2 years) were recognized at operation, but relief of the anomalies was compromised by the small size of aorta and limited visibility of the midventricular region. Reoperation was required 3 years later for complete relief of LVOTO and mitral valve repair.

Key to recognition of subvalvular anomalies is excellent intraoperative exposure, strong lighting with a fiber-optic headlight, and magnification with optical loupes, combined with a quiet, dry field. Elevation of the aortic valve commissures by sutures attached to the wound edges or drapes is very helpful in improving exposure, especially in massively thickened hearts that lie transversely in the chest. In most cases, the subvalvular region is not well seen, or not seen at all, until the classical myectomy is completed. Visualization of the subvalvular region improves as the several additional resections of an extended myectomy are performed. Resection at midventricular level is facilitated by use of long rongeurs or biopsy forceps. Sharp-toothed rake retractors aid retraction and resection of the septal bulge and the apical third of the septum on the right side of the septal trough. In our experience, the latter is not accompanied by an increased incidence of permanent complete heart block, and it allows more complete midventricular resection. Additionally, it more consistently provides absent postmyectomy gradients and absent chordal SAM.

The mechanism of SAM is controversial and concepts include the Venturi (pull) effect ${ }^{19,20}$ and a drag (push) effect. $^{21,22}$ Whatever the relative roles these mechanism may play in creating dynamic LVOTO in HOCM, the obstruction and associated mitral regurgitation are relieved by classical septal myectomy in most patients. However, when associated anomalies of mitral subvalvular apparatus are present, additional measures may be required.

In conclusion, symptomatic patients with HOCM associated with anomalous papillary muscles or chordae can be successfully treated without mitral valve replacement by surgical relief of the anomalies and an extended septal myectomy; early mortality is low, LVOTO and mitral regurgitation are significantly reduced, and late results are excellent.

We thank the Mayo Clinic Division of Biostatistics for statistical support and Judy K. Lenoch for advice and assistance with data collection and analysis.

\section{References}

1. Maron BJ. Hypertrophic cardiomyopathy. Lancet. 1997;12;350:12733.

2. Nishimura RA, Giuliani ER, Brandenburg RO, Danielson GK. Myocardial disease: hypertrophic cardiomyopathy. In: Giuliani ER, Gersh BJ, McGoon MD, Hayes DL, Schaff HV, editors. Mayo Clinic practice of cardiology. 3rd ed. St Louis: Mosby; 1996. p. 689-711.

3. Grigg LE, Wigle ED, Williams WG, Daniel LB, Rakowski H. Transesophageal Doppler echocardiography in obstructive hypertrophic cardiomyopathy: clarification of pathophysiology and importance in intraoperative decision making. J Am Coll Cardiol. 1992;20:42-52.

4. Maron BJ, McKenna WJ, Danielson GK, Kappenberger LJ, Kuhn HJ, Seidman CE, et al. American College of Cardiology/European Society of Cardiology Clinical Expert Consensus Document on Hypertrophic Cardiomyopathy: a report of the American College of Cardiology Foundation Task Force on Clinical Expert Consensus Documents and the European Society of Cardiology Committee for Practice Guidelines. J Am Coll Cardiol. 2003;42:1687-713.

5. Morrow AG, Roberts WC, Ross J Jr, Fisher RD, Behrendt DM, Mason DT, et al. Obstruction to left ventricular outflow. Current concepts of management and operative treatment. Ann Intern Med. 1968;69:125586.

6. Theodoro DA, Danielson GK, Feldt RH, Anderson BJ. Hypertrophic obstructive cardiomyopathy in pediatric patients: results of surgical treatment. J Thorac Cardiovasc Surg. 1996;112:1589-97.

7. Mohr R, Schaff HV, Danielson GK, Puga FJ, Pluth JR, Tajik AJ. The outcome of surgical treatment of hypertrophic obstructive cardiomyopathy. Experience over 15 years. J Thorac Cardiovasc Surg. 1989; 97:666-74

8. Robbins RC, Stinson EB. Long-term results of left ventricular myotomy and myectomy for obstructive hypertrophic cardiomyopathy. J Thorac Cardiovasc Surg. 1996;111:586-94.

9. Heric B, Lytle BW, Miller DP, Rosenkranz ER, Lever HM, Cosgrove DM. Surgical management of hypertrophic obstructive cardiomyopathy. Early and late results. J Thorac Cardiovasc Surg. 1995;110:195206.

10. Brunner-La Schonbeck MH, Rocca HP, Vogt PR, Lachat ML, Jenni R, Hess OM, et al. Long-term follow-up in hypertrophic obstructive cardiomyopathy after septal myectomy. Ann Thorac Surg. 1998;65: 1207-14.

11. Schoendube FA, Klues HG, Reith S, Flachskampf FA, Hanrath P, Messmer BJ. Long-term clinical and echocardiographic follow-up after surgical correction of hypertrophic obstructive cardiomyopathy with extended myectomy and reconstruction of the subvalvular mitral apparatus. Circulation. 1995;92:II122-7.

12. Klues HG, Maron BJ, Dollar AL, Roberts WC. Diversity of structural mitral valve alterations in hypertrophic cardiomyopathy. Circulation. 1992;85:1651-60.

13. Klues HG, Roberts WC, Maron BJ. Anomalous insertion of papillary muscle directly into anterior mitral leaflet in hypertrophic cardiomyopathy. Significance in producing left ventricular outflow obstruction. Circulation. 1991;84:1188-97.

14. Maron BJ, Nishimura RA, Danielson GK. Pitfalls in clinical recognition and a novel operative approach for hypertrophic cardiomyopathy with severe outflow obstruction due to anomalous papillary muscle. Circulation. 1998;98:2505-8.

15. Reis RL, Bolton MR, King JF, Pugh DM, Dunn MI, Mason DT. Anterior-superior displacement of papillary muscles producing obstruction and mitral regurgitation in idiopathic hypertrophic subaortic stenosis-operative relief by posterior-superior realignment of papillary muscles following ventricular septal myectomy. Circulation. 1974;50:II181-8.

16. Messmer BJ. Extended myectomy for hypertrophic obstructive cardiomyopathy. Ann Thorac Surg. 1994;58:575-7.

17. Zhu WX, Oh JK, Kopecky SL, Schaff HV, Tajik AJ. Mitral regurgitation due to ruptured chordae tendineae in patients with hypertrophic obstructive cardiomyopathy. J Am Coll Cardiol. 1992;20:242-7.

18. Krajcer Z, Leachman RD, Cooley DA, Coronado R. Septal myotomymyomectomy versus mitral valve replacement in hypertrophic cardiomyopathy. Ten-year follow-up in 185 patients. Circulation. 1989;80: I57-64. 
19. Wigle ED, Rakowski H, Kimball BP, Williams WG. Hypertrophic cardiomyopathy. Clinical spectrum and treatment. Circulation. 1995; 92:1680-92.

20. Cape EG, Simons D, Jimoh A, Weyman AE, Yoganathan AP, Levine RA. Chordal geometry determines the shape and extent of systolic anterior mitral motion: in vitro studies. J Am Coll Cardiol. 1989;13: 1438-48.

21. Sherrid MV, Chu CK, Delia E, Mogtader A, Dwyer EM Jr. An echocardiographic study of the fluid mechanics of obstruction in hypertrophic cardiomyopathy. J Am Coll Cardiol. 1993;22:816-25.

22. Sherrid MV, Gunsburg DZ, Moldenhauer S, Pearle G. Systolic anterior motion begins at low left ventricular outflow tract velocity in obstructive hypertrophic cardiomyopathy. J Am Coll Cardiol. 2000;36:134454.

\section{Discussion}

Dr William G. Williams (Toronto, Ontario, Canada). I appreciate the privilege of discussing Dr Dearani's excellent presentation. He has highlighted an important subset of hypertrophic cardiomyopathy patients in whom there was an uncommon but important mechanism of obstruction.

I would like to take this opportunity also to express my admiration for the senior author, Dr Gordon Danielson. Throughout his distinguished career at the Mayo Clinic, Dr Danielson has provided exemplary patient care while contributing his considerable intellectual skills in solving many problems in congenital heart surgery. He has established surgical myectomy as the gold standard for treatment of obstructive form of hypertrophic cardiomyopathy.

Hypertrophic cardiomyopathy affects as many as 1 person in 500 in the general population. Most patients referred for surgery have the obstructive form of the disease. Typically the obstruction is in the outlet, though it may be at midventricular or apical level.

Outlet obstruction is associated with systolic anterior motion of the mitral valve, and this SAM increases the severity of the obstruction and causes mitral regurgitation. Successful surgical myectomy relieves the obstruction and almost invariably improves or resolves the mitral regurgitation.

Mitral valve repair or replacement is indicated only when the mitral regurgitation is independent of the obstruction, in which case it usually precedes the SAM septal contact. In our own myectomy experience for patients with hypertrophic cardiomyopathy, among 379 patients, mitral valve repair was required only in 11 and replacement in 2 patients.

Dr Dearani and his colleagues have demonstrated that a subset of patients with mitral valve anomalies can be managed successfully with a more extensive modified myectomy, and repair or replacement of the mitral valve is unnecessary. This subset of patients is particularly important to identify, as their obstruction may not be associated with the SAM.

Preoperative recognition of the papillary muscle anomalies they describe is especially important in the current era of enthusiasm for alcohol ablation by our interventional colleagues because successful alcohol ablation unlikely.

Dr Dearani stressed the intraoperative identification of this anomaly. My first question is, can this mechanism of obstruction be reliably diagnosed preoperatively? In the 1991 work by Klues, Roberts, and Maron, it was recognized only in 1 of the 10 preoperatively.

Although we are confident that surgical myectomy for patients with outlet obstruction is highly efficacious, I am less confident that surgical treatment of isolated midventricular obstruction is beneficial. Did any of these patients have isolated midventricular obstruction, and in that situation would you recommend myectomy?

Because the modified extended myectomy you describe has been successful without increasing the incidence of AV block, would the authors recommend this modified myectomy for all patients in whom the outlet obstruction extends to the midventricular level, or indeed in all patients with obstructive hypertrophic cardiomyopathy?

I congratulate you for clarifying both the identification and management of this important subset of patients with obstructive hypertrophic cardiomyopathy.

Dr Dearani. Thank you, Dr Williams, for your kind comments. It is possible to identify anomalies of the mitral subvalvular apparatus such as direct papillary muscle insertion into the mitral valve with either preoperative transthoracic echocardiography or intraoperative transesophageal echocardiography. Images obtained in the parasternal long-axis or apical cross-sectional planes may suggest that a papillary muscle and the mitral valve are contiguous, without evidence of chordae between the head of the papillary muscle and the mitral valve. In addition, there may be fusion of the papillary muscle to the ventricular septum. Systolic anterior motion is often absent or mild and the level of obstruction is usually at the midventricular level. It should be noted, however, that identification of these anomalies of the mitral subvalvular apparatus can be difficult even for experienced echocardiographers.

Many of the patients in this series had midventricular obstruction. We are able to perform an extensive resection at the midventricular level with our current techniques. Consequently, we do advise left ventricular septal myectomy when isolated midventricular obstruction is identified on echocardiographic studies. We are currently examining the results of patients who have undergone myectomy for isolated midventricular obstruction.

We have gained experience now with more than 700 patients who have undergone myectomy over the last 3 decades. Our technique of septal myectomy has evolved from the classic Morrow myectomy to a more extended myectomy. This includes resection apically to the bases of the papillary muscles and resection leftward back toward the mitral valve. The apical third of the right side of the septum is then resected, effectively making a much wider trough at the apex than the base. The base of the resected area is then deepened with a rongeur. In general, we perform the extended myectomy in all patients undergoing operation for obstructive hypertrophic cardiomyopathy.

When an abnormal mitral subvalvular apparatus is present, we divide all attachments that exist between the lateral edge of the anterior leaflet and septum and divide all attachments between the papillary muscle(s) and septum. It is important to maintain intact all chordal attachments to the leading edge of the anterior leaflet. The presence of a direct papillary muscle insertion into the anterior mitral leaflet is often accompanied by fusion of the papillary muscle to the septum. Surgical myectomy is performed in the extended fashion and in addition, the papillary muscle is incised of the septum down to its base.

Dr Richard A. Jonas (Boston, Mass). Joe, this is a 27-year series with 292 patients, but your mean follow-up is 2.8 years, and yet you state that your follow-up was $96 \%$ complete. Can you 
clarify for us whether this was a cross-sectional follow-up, which is really what would be required to know whether this approach was successful over the long term? Do you have a time-related sense or a time-related analysis as to the risk of recurrent outflow tract obstruction or mitral valve problem? Because your practice, like ours, is a referral practice, many of these patients come from cardiologists around the country and around the world, and there is a tendency if there is a recurrence for parents to say, "We went to the Mayo Clinic, and now the problem has come back. We don't want to go back there. We want to go somewhere else." So I'm just a little bit concerned if this is not a cross-sectional follow-up that you may be missing quite a few recurrences.

Dr Dearani. All the patients but 2 had follow-up within 1 year of the end of the study period (August 2002). Although this is a review of 25 years' experience of our surgical series, we first recognized this anomaly in 1989 . We modified our surgical technique in the mid-1990s to treat this subset of patients. Thus, we found most of the patients with these anomalies very recently. In fact, 32 patients $(57 \%)$ were operated on after 2000 . This explains the mean follow-up of only 2.8 years.

Dr Constantine Mavroudis (Chicago, Ill). Joe, that was a beautiful presentation. I have 3 questions, mostly relating to the technical aspects of exposure. The first one, though, is not about exposure.

Is this the largest series of its kind in the literature of abnormal papillary muscles that has been identified? Is that accurate?

Dr Dearani. Yes.

Dr C. Mavroudis. It is the largest?

Dr Dearani. Yes.

Dr C. Mavroudis. And then the next question. Occasionally I perform a transection of the aorta to expose the aorta and look directly down into the left ventricular outflow tract. I wonder if that's what you do, or how do you expose the aorta in difficult or small cases?

And the last question I want to ask you is, do you use any retractors that are mounted on the side and so forth, so you can get an unobstructed view without anyone moving anything to look at what you're doing?

Dr Dearani. Yes. There are many maneuvers that we utilize to facilitate a satisfactory, extensive myectomy. A transverse aortotomy is made, carried rightward toward the noncoronary sinus and down to the aortic annulus. The aortic valve commissures are suspended with pledgeted sutures to maximize exposure of the hypertrophied septum and anterior mitral leaflet. Inspection of the anatomy is performed with identification of the line of apposition of the anterior mitral leaflet to the septum (friction lesion). Optimal visualization of the ventricular septum is facilitated by posterior displacement of the left ventricle with a sponge forceps. In addition, a small rake retractor can be used to engage the distal septum so that it can be pulled cephalad toward the aortic annulus. A small vein retractor is used to engage the superior aspect of the initial trough. Gentle lateral retraction is performed with this retractor and at the same time it protects the aortic valve from injury. A small cherry tip sucker placed through the aortotomy is used to retract the anterior mitral leaflet and chordae posteriorly away from the septum while performing the myectomy so to avoid injury to these structures. We only use handheld retractors with gentle retraction in various directions to facilitate exposure during the course of the myectomy. 